\title{
El concejo y las fiestas de la Inmaculada en Málaga. 1640
}

\author{
FEDERICo FERnÁNdEZ Basurte*
}

La fiestas en honor de la Inmaculada Concepción entroncan directamente con la tradición de la iglesia española centrada en la figura de la Virgen. Su significado, importancia y manifestaciones en la vida ciudadana están estrechamente relacionadas con el hecho de que el municipio participe activamente en su celebración.

Para realizar este estudio nos hemos movido en un marco cronológico definido por los siglos XVI y XVIII, centrándonos especialmente en el setecientos, dada la pujanza que alcanzó el movimiento contrarreformista y, con él, el fervor mariano.

La documentación manejada es fundamentalmente la municipal, pues el objetivo propuesto es conocer las repercusiones que el movimiento inmaculadista tiene en la ciudad, las cuales se pueden observar en el caso de las celebraciones festivas organizadas y financiadas por el concejo para honrar este misterio, uno de cuyos ejemplos concretos son las de 1640.

APROXIMACIÓN A LOS ORIGENES DE LAS FIESTAS DE LA INMACULADA

El 8 de diciembre de 1854, el Papa Pio IX definió y proclamó el dogma de la Inmaculada Concepción de María, poniendo así punto y final a siglos de reivindicaciones hechas en este sentido por las Iglesias de distintas naciones $y$, de un modo especial, por la española.

* Universidad de Málaga. 
Tendríamos que remontarnos a tiempos antiguos para encontrar los primeros indicios de la existencia de esta creencia tan extendida y arraigada entre el pueblo. Ya en época medieval, en la que podemos situar el inicio del mencionado proceso reivindicativo, tres eran los temas fundamentales de la mariología de la iglesia mozárabe: la maternidad divina virginal, la asociación a Cristo de la figura de María y, precisamente, la inmaculada concepción de la Virgen. En este período histórico, las grandes figuras de la patrología hispana - San Isidoro, San Leandro, San Ildefonso, etc. - hicieron sus aportaciones a la definición de dichos temas. Sin embargo, la Iglesia no se definió claramente, de modo que la ambigüedad y las disputas en torno a su aceptación o su rechazo fueron comunes, no sólo en la Edad Media, sino que habrían de prolongarse en la Época Moderna.

En los reinos de España, la jerarquía eclesiástica si asumió la defensa de los mencionados misterios, que contaban con una gran veneración por parte del pueblo, lo cual se pone de manifiesto en la temprana implantación de la celebración de festividades tales como la Purificación, la Asunción y la Inmaculada.

El movimiento inmaculadista toma auténtica carta de naturaleza en torno al siglo XVI, cuando los monarcas de los reinos hispanos se ponen a la cabeza de la reivindicación ante Roma de su definición y, en última instancia, de su proclamación dogmática.

En plena Contrarreforma, este tema se convierte en argumento fundamental frente a los heterodoxos. Si la Reforma había cuestionado el culto a la Virgen y a los santos, la validez del concepto tradicional de los sacramentos, etc., el espíritu tridentino llevará a potenciar el culto y la devoción mariana, junto a la exaltación de la Eucaristía y la difusión de las figuras de determinados santos, entre otras medidas y actitudes. En esta línea se multiplican los tratados sobre cuestiones mariológicas y crece la devoción hacia la figura de María, lo que se pone de manifiesto en la propia evolución de su iconografía. En un primer momento, cuando la ambigüedad respecto al tema es mayor, prima la representación alegórica del misterio. Pero a partir del siglo XV se acuña y perfila la iconografía de la Inmaculada, cuya representación habrá de constituir uno de los instrumentos más eficaces para enfervorizar al pueblo.

En el caso concreto de Málaga, según señala Andrés Llordén, para 1510 ya se pueden encontrar rastros de la celebración en la catedral de 
solemnes actos de culto en la fiesta de la «Pura y Limpia Concepción", según la terminología de la época ${ }^{1}$.

Podemos hallar, de igual modo, numerosas muestras y manifestaciones de tal devoción a nivel particular o privado. A este respecto, Llordén nos señala una serie de ejemplos ilustrativos referentes a las numerosas fundaciones y donaciones que denotan la creciente inclinación religiosa de la sociedad hacia este tema. Se trata de varios testamentos y documentos notariales datados a lo largo del siglo XVI y principios del XVII, en los que los testadores o los donantes fundan una fiesta anual en honor a la Inmaculada Concepción, dotándola con sustanciosas aportaciones económicas. Por lo general, se celebraba el mismo día de la conmemoración de dicho misterio o en su octava, y un gran número de ellas tienen en común el que quedan establecidas en el Convento de la Victoria. Este hecho, por otra parte, no es extraño ya que se trata de un lugar de culto mariano por excelencia, como se pone de manifiesto con la consagración en 1559 de una capilla a la Inmaculada ${ }^{2}$. De igual modo, en el Convento de la Merced se funda en 1595 otra capilla dedicada a la misma advocación ${ }^{3}$.

\section{EL CONCEJO, PROMOTOR DE LAS CELEBRACIONES}

Aparte de estas manifestaciones que corren a cargo de particulares, hallamos otras, aún más significativas y de mayor repercusión, que podríamos considerar públicas, por cuanto son promovidas por el cabildo municipal, y colectivas, porque engloban al pueblo en general, que actúa a la vez como espectador-receptor y protagonista. Se trata de las fiestas, cuyo devenir está marcado por la propia evolución del movimiento inmaculadista en lo que se refiere a la reivindicación de la definición dogmática. Cada avance en este sentido se celebra con grandes demostraciones, ya sea por propia iniciativa de los cabildos - municipal y eclesiástico-, ya por indicación de la Corona, que, como hemos señalado antes, estaba muy interesada en aicanzar del Papa dicha definición.

En 1615, Paulo $V$ concede indulgencias a la oración a la Inmaculada Concepción y, en 1616, prohíbe sostener en público doctrinas contrarias

\footnotetext{
Llorden, A., «La ciudad de Málaga y la devoción a la Inmaculada Concepción de la Virgen María», Gribralfaro, m. ${ }^{\circ} 4-5$ (1954), págs. 220-222.

2 lbidem, pág. 221.

3 Archivo Histórico del Museo de Artes Populares de Málaga (Díaz de Escovar) (M AA PP), caja 122.
} 
a este misterio. Son famosas las respuestas que estas medidas pontificias tuvieron en Sevilla y en Granada, con funciones religiosas, manifestaciones festivas y multitudinarias procesiones. Aunque menos conocidas, la ciudad de Málaga también celebró en septiembre de 1616 solemnidades con misas y sermones, repiques, fuegos y luminarias, y procesiones muy concurridas ${ }^{4}$.

Esta conmemoración se renovará anualmente en la catedral. Sin embargo, las grandes demostraciones festivas públicas y colectivas, parece que no son organizadas todos los años con la misma ostentación y lujo de elementos y actos, o al menos eso nos hace pensar el hecho de que la documentación municipal, en concreto las Actas Capitulares, recojan sólo de forma intermitente estas celebraciones.

A mediados del siglo XVII se reanudan con fuerza las gestiones con Roma en aras de conseguir la pretendida definición. En este momento se van a multiplicar los juramentos de defensa pública y privada de la Inmaculada Concepción de la Virgen. Las órdenes militares, los concejos de las ciudades y los cabildos eclesiásticos, instituciones y corporaciones de religiosos seglares, se suceden en la proclamación del voto concepcionista. En 1654 sendos cabildos malacitanos, el eclesiástico y el municipal, realizan juntos el juramento de defensa de dicho misterio.

La iniciativa parte del municipio, que toma tal decisión en vista de que otras ciudades ya han proclamado su voto. Esta determinación, junto con la indicación al respecto hecha por el cardenal de la Cueva, obispo de la diócesis, mueven al cabildo catedralicio a acordar igualmente que se jure y vote defender el misterio de la Inmaculada Concepción en el día de su fiesta ${ }^{5}$.

Ambas instituciones inician los preparativos para efectuar dicha proclamación de forma conjunta y en el marco de un amplio programa de celebraciones. Éste incluiría un solemne octavario en la catedral a partir del día ocho de diciembre, fecha en la que se realizaría el juramento. El último día del octavario habría de celebrarse una procesión en la que participarian las dos corporaciones capitulares, las parroquias, las comunidades de religiosos y todas las cofradías de la ciudad, a semejanza de la del día del Corpus Christi. Dos días antes, los regidores, ministros y oficiales de la ciudad participarían en un desfile, con las insignias del Ayuntamiento y el acompañamiento musical de los atabales, para publicar

LORDen, A., Op. cit., págs. 224-225

5 Archivo de la Catedral de Málaga (ACM), Actas Capitulares (AACC), vol. 26, fol. 256v y fol. 336 . 
el voto de los dos cabildos. Estas celebraciones se completarían con los elementos típicos de las fiestas de la época: luminarias y fuegos, máscaras y danzas, componentes lúdicos de esta celebración religiosa que hacen las delicias de chicos y grandes, contribuyendo a crear el ambiente festivo que vive la ciudad durante esos días ${ }^{6}$.

El amplio programa será costeado por la ciudad con cargo a sus rentas de propios. Además, los miembros del concejo, considerando «todos los caminos que puede tener (la ciudad) para eternizar más su devoción y asistir en vida y muerte con ella y en la Santa Iglesia», solicita al cabildo eclesiástico que le permita correr con los gastos de la colocación de la imagen de la Purísima en la capilla de San Gregorio de la catedral, así como que se le otorge el patronato de la misma?.

Tanto la ciudad como el cabildo catedralicio tendrán nuevas oportunidades para hacer públicas manifestaciones en torno al mismo objeto por medio de fiestas de las que se hace partícipe al pueblo. Tales celebraciones, como sobre todo el hecho de que la ciudad se sume a cuantas solicitudes de adhesión y apoyo se le hacen, tienen un acusado carácter político, ya que tales requerimientos parten de la Corona, como se constata en 1662 cuando, a instancias de Felipe IV, el papa Alejandro VII concede un Breve definiendo el misterio de la Concepción de la Virgen, o en 1761, al declarar Clemente XIII a la Inmaculada Concepción Patrona de los Reinos de España, atendiendo a la petición de Carlos $11{ }^{8}$.

Otro dato que nos habla de la importancia del tema que nos ocupa, especialmente por lo que se refiere a la mentalidad religiosa popular, es la profusión de capillas callejeras -englobando bajo este nombre tanto a las capillas propiamente dichas como a hornacinas, azulejos, retablos, etc.- en las que se veneran imágenes de la Virgen bajo la advocación de la Purísima Concepción.

Sin entrar en profundidad en el estudio de las capillas callejeras, podemos afirmar que éstas constituyen uno de los elementos fundamentales que contribuyen a la sacralización del espacio urbano. Estos espacios se abren en cualquier esquina, a la altura del transeúnte, en la fachada de una iglesia, de una casa particular o de un edificio público, sirven para aproximar lo divino al hombre de la época, obsesionado por su salvación y cuya vida cotidiana está totalmente marcada por gestos y prácticas tales

\footnotetext{
6 Archivo Municipal de Málaga (AMM), Actas Capitulares (AACC), vol. 70, fols. 245v-248, 250-251v, 256v-258v.

lbidem.

- LloRden, A., Op. cit., págs. 243-245 y 261.
} 
como las ofrendas de flores y luces, los exvotos y las visitas a estas capillas para orar ante las efigies.

Además, hemos de tener en cuenta que nos estamos moviendo en el marco de la cultura del Barroco, cultura eminentemente urbana en la que priman lo simbólico, la puesta en escena y la manifestación pública. Por ello alcanzan tanto auge las procesiones y otras solemnidades litúrgicas, así como las fiestas -ya sean religiosas o profanas-, en las que se despliegan recursos destinados a conmover, a despertar sentimientos, en el caso que nos ocupa sentimientos religiosos. Esta tendencia tiene su traslación a la vida cotidiana en las capillas callejeras ${ }^{9}$.

Después de Trento, al potenciarse la devoción mariana en general, se produce la multiplicación de los espacios de este tipo dedicados al culto de la Virgen. Es de resaltar el hecho de que las dos capillas que se levantaron en el recinto portuario fueron puestas bajo la advocación de la Inmaculada Concepción. En 1593 se construyó la primera, dedicada a la Inmaculada bajo la significativa denominación de Ntra. Sra. de Puerto Salvo o Puerto Seguro, y cuyo fin era el que oyeran misa en ellas las gentes del mar ${ }^{10}$. Por su ubicación, estaría a medio camino entre la función puramente devocional y el carácter propagandístico, que tantas veces queda expresado en la documentación municipal cuando se resalta la necesidad de hacer la mayor demostración posible de fe, «por ser la ciudad puerto de mar y hallarse a la vista de tantas naciones y muchas dellas sin la profesión de la fe católica»" ${ }^{11}$. En 1717, al ampliarse el muelle de Levante, se erige una nueva capilla - cuya inauguración tiene lugar en i725--, que es la que hoy se conserva aunque trasladada de emplazamiento, y que se dedica también a la Purísima Concepción, al quedar sin uso la antigua del muelle viejo ${ }^{12}$.

Otras muestras de este tipo que podemos citar son: el altar situado en un balcón de la casa que, cerca de la calle Ropería Vieja, estaba

Acerca de este tema de las capillas y retablos de culto callejeros, resulta sumamente interesante lo que al respecto aportan en sus respectivas obras, para el caso de Málaga, CAmacho Martinez, R., Málaga Barroca. Arquitectura religiosa de los siglos Xvil y xvil. Málaga 1981, y Morales Folguera, J. M., La Málaga de los Borbones. Málaga 1986. Un estudio exhaustivo sobre el particular, centrado en la ciudad de Sevilla, es el de FERNÁNDEZ DE PAZ, E., Religiosidad popular sevillana a través de los retablos de culto callejero. Sevilla 1987.

10 AMM, Col. Escribanía de Cabildo, libro 58, fols. 125-126v. MAAPP, caja 298.

Cfr. Cabrera Pablos, F., "Construcción de la capilla del puerto de Málaga», Jábega, 44 (1983), págs. 51-61. AtenciA, E., "La capilla del puerto de Málaga", Jábega, 11 (1975), págs. 29 -31.

AMM, AACC, vol. 91, fols. 20-21 lbidem, Col. Contaduría de Cabido (Propios, censos, pósitos, contribuciones y repartos) (C. de C.) leg. 41, s/f. Traslado de una carta del Rey incluida en el informe sobre las cuentas del Corpus Christi y Santos Mártires del año 1659.

12 MAAPP, caja 298, Cfr. Camacho Martínez, R., op. cit, págs. 261-264. 
destinada al Sargento Mayor de la Ciudad ${ }^{13}$; la capilla del interior de la Alhóndiga $^{14}$; la ubicada entre la calle Nueva y la de San Juan de los Reyes, seguramente donde hoy se levanta la iglesia de la Concepción, de la cual se tiene constancia ya en 1619, y cuya construcción con toda probabilidad se remontaría al siglo XV ${ }^{15}$. Además de los anteriores, habría numerosos ejemplos de imágenes de ia Inmaculada expuestas al culto en plena calle, promovidas y conservadas por particulares, como la hornacina dispuesta desde 1740 en la fachada lateral de una casa de la Cortina del Muelle, abriéndose al Portigo de los Abades ${ }^{16}$.

Otra muestra de su importancia la constituye la fundación de cofradías bajo esta advocación. Aparte de las surgidas en el Hospital de Santa Ana, en los Mártires y en San Pablo, sin duda la más significativa es la Hermandad de la Pura y Limpia Concepción.

Esta hermandad, de la que no conocemos la fecha exacta de su constitución, fue erigida con bastante probabilidad en torno a las dos primeras décadas del xVII en el convento franciscano de San Luis el Real ${ }^{17}$. A lo largo de la centuria esta cofradía alcanzó una gran importancia en el concierto cofrade de la ciudad, lo que queda demostrado, entre otras cosas, por la fundación de varias hermandades filiales surgidas en su seno -Humildad y Paciencia, Columna, Cruz a Cuestas, Santo Sudario-, así como por incorporar diversos pasos en su estación de penitencia, entre los que podemos citar el Lavatorio y San Pedro, la Coronación de Espinas y la Cena.

Gracias a las gestiones efectuadas por los hermanos, la imagen titular de Ntra. Sra. de la Pura y Limpia Concepción fue colocada en el retablo de la capilla mayor de San Luis el Real. Desde su fundación, tanto la hermandad matriz como sus filiales, contaron con el apoyo y la protección de elementos del estamento nobiliar de la ciudad ${ }^{18}$.

En general, aunque no estuvieran bajo la advocación concepcionista, la mayor parte de las cofradías y hermandades adoptaron el compromiso del voto o juramento en defensa de la Inmaculada Concepción de María,

\footnotetext{
13 MAAPP, caja 298.

14 Ibidem.

15 Bejarano Robles F., Las calles de Málaga. De su historia y ambiente. Málaga 1984, vol. I, pág. 63 y vol. II, págs. 569-570.

${ }_{16}$ lbidem, pág. 750.

17 Llorden, A. y Souviron, S., Historia Documental de las Cofradias y Hermandades de Pasión de la Ciudad de Málaga. Málaga, 1969, pág. 452.

18 Archivo Histórico Provincial de Málaga (AHPM), Escribanía de Antonio Vargas Machuca, año 1675, fols. 607-610. Cfr. LloRden, A., y Souviron, S., op. cit, págs. 465-468.
} 
como se pone de manifiesto en las reglas o estatutos de este tipo de corporaciones.

\section{LAS FIESTAS DE 1640 EN MÁLAGA}

La fiesta, ya sea religiosa o profana — si es que para la época que nos ocupa se puede hacer una distinción clara-, constituye un objeto de estudio extraordinario por la información que nos puede aportar acerca de los grupos sociales que participan en ella. Se trata de un hecho especialmente ilustrativo por cuanto se trata de un momento en el que la colectividad expresa, a través de símbolos, su concepción imaginaria del mundo - sus miedos, sus inquietudes, su concepto de la organización social, etc.-. Además, la fiesta es un medio de primera magnitud para la transmisión de determinados mensajes y para la implantación de ciertos principios ideológicos por parte de sus promotores.

Una de las características de la cultura del Barroco es el hecho de que en una buena medida sus manifestaciones estén impulsadas y promovidas por los elementos más poderosos de la sociedad, que pretenden defender sus intereses y privilegios, activando una serie de resortes destinados a superar las posibles fuerzas de desviación o de oposición al régimen establecido. Así, en la fiesta barroca se expresa la existencia de una unidad trascendente que aglutina lo religioso, lo político, lo público, lo privado, etc., que autoriza y legitima, por su propia esencia sacralizada, a aquellos sectores sociales que ejercen el poder ${ }^{19}$.

Por otra parte, la cultura del Barroco también queda definida por su carácter eminentemente urbano en el que se concede gran importancia a la ostentación, a la manifestación pública del poder, de la riqueza, de las virtudes morales o de la piedad religiosa ${ }^{20}$. Estas demostraciones estarian también muy relacionadas con la estratificación social, ya que, a través de su actuación en ocasiones como en las fiestas, los estamentos superiores dejan bien claras sus diferencias respecto al resto de la sociedad.

Es importante señalar también, como ya hemos referido antes, su aspecto propagandístico, dadas las características de una ciudad portuaria como Málaga.

\footnotetext{
19 Pérez del Campo, L. y Quintana Toret, F. J., Fiestas Barrocas en Málaga. Málaga 1985 pág. 29.

20 Maravall, J. A., La cultura del Barroco. Barcelona 1983, pág. 250.
} 
A través del estudio del informe de las cuentas de las fiestas celebradas en mayo de 1640 «en honor de la Pura y Limpia Concepción de la Virgen Santísima", costeadas por el cabildo municipal, podemos acercarnos a los elementos y al significado de una muestra de estas festividades barrrocas a las que nos hemos referido, así como a una manifestación de la devoción inmaculadista en Málaga ${ }^{21}$.

A lo largo del año, se suceden en la ciudad diversas celebraciones religiosas en honor de distintos Santos y advocaciones cristíferas y marianas, considerados protectores de la ciudad ${ }^{22}$. Pero entre todas destacan tres fechas por el esfuerzo organizativo y los recursos económicos a ellas destinados por el ayuntamiento: los Santos Mártires - primitivos patronos de Málaga-, San Luis Obispo (19 de agosto) — conmemoración de la toma de la ciudad por los Reyes Católicos-y, sobre todo, el Corpus Christi.

A medio camino entre estos dos grupos o tipos de celebraciones se nos presentan las de la Inmaculada, ya que sin ser una más entre las numerosas festividades a las que acude corporativamente el concejo, a las cuales ayuda económicamente librando una subvención, tampoco llegan a alcanzar las cotas de gastos que suponen las otras tres celebraciones mayores, y de un modo especial la eucarística.

No obstante, estas fiestas de la Inmaculada responden al modelo organizativo de las fiestas mayores de la ciudad, por lo cual se eligen, entre los regidores, unos diputados - en este caso concreto cuatro- para que se encarguen de la preparación, al tiempo que se les concede una cantidad de la que pueden disponer para los gastos que se ocasionen, los cuales habrán de justificar después ante el cabildo por medio de un informe que se somete a su aprobación.

Hemos de señalar que las fiestas de la Concepción no tenían lugar con la misma ostentación y elementos todos los años. Aunque la solemnidad religiosa en la catedral parece mantener una uniformidad, las fiestas públicas organizadas con tal ocasión no presentan una continuidad anual.

En esta ocasión, como muestran las actas capitulares ${ }^{23}$ y como recoge el traslado del acuerdo municipal que se adjunta al informe de cuentas ${ }^{24}$,

AMM, Col. C. de C., leg. 41, s/f.

22 FERNÁNDEZ BASURTE, F., "Reacciones piadosas colectivas ante las catástrofes públicas en la Málaga del sigloxvII. La epidemia de 1649 y el terremoto de 1680», en Mentalidad e ideología en el Antiguo Régimen, Actas de la II Reunión Científica de la Asociación Española de Historia Moderna. Murcia 1993, 211-224.

${ }^{23}$ AMM, AACC, vol. 56, fols. 79v-80.

24 Ibidem, Col. C. de C., leg. 41, s/f. 
la iniciativa parte del cabildo eclesiástico. Los capitulares de la catedral informan a la ciudad acerca de su pretensión de celebrar con toda solemnidad la fiesta de la Inmaculada, lo que por su parte se concretaría, en este caso, en una función religiosa en la catedral. Al tiempo solicitan a la ciudad que corresponda con «la demostración que es justo», es decir, que se organice un programa de festejos que con el lucimiento y la ostentación propios de esplendor y relevancia al día señalado.

A partir de este momento el cabildo pone en marcha la maquinaria organizativa a la que nos referíamos. Se nombran cuatro diputados, pero en realidad el peso de la organización lo llevará en este caso el escribano del cabildo, Alonso Ortiz de Peralta, quien recibe los 300 ducados librados a los regidores diputados y quien presenta en última instancia las cuentas para su aprobación.

De acuerdo con la mentalidad de la época, el papel de promotores y organizadores de la fiesta, sirve a los miembros del cabildo municipal -integrado por los elementos de la oligarquía local, es decir, por elementos de la nobleza de caballeros o hijosdalgos - para cumplir con las responsabilidades y obligaciones morales que su pertenencia al estamento nobiliar les confiere, al tiempo que les revertirá en una mayor consideración social, en un mayor reconocimiento público, en tanto en cuanto resulten más suntuosos los actos por ellos organizados.

A diferencia de las ocasiones en las que la fiesta está conjuntamente organizada por ambos cabildos, como en el caso antes referido de la proclamación del voto concepcionista en el que, por ejemplo, el concejo participa de la propia organización de la función religiosa, disponiendo la presencia y asignando un lugar concreto a la representación de las compañias de milicias, o toma parte en el establecimiento de la composición y el itinerario de la procesión, en esta ocasión las responsabilidades organizativas están bien delimitadas y la ciudad se encarga estrictamente de las demostraciones festivas ajenas a la propia solemnidad en la catedral.

La única referencia que se hace en las cuentas a los gastos ocasionados por la función religiosa es la que corresponde al arreglo de uno de los bancos en los que se sienta la ciudad en la catedral, hecho que también nos habla del juego de preeminencias y lugares de honor tan característico de la mentalidad de la época.

Con el apoyo de la información que proporcionan las actas capitulares, las partidas recogidas en este informe nos permiten hacer una reconstrucción aproximada del programa de actos y de los elementos propios de una fiesta de este tipo. 
El día de la víspera se organiza un desfile que, al son de los timbales de atabaleros a caballo, anuncia al pueblo la celebración. En esta procesión cívica, de cuyos detalles se encarga al portero mayor del cabildo, suelen estar presentes las insignias del Ayuntamiento y participan en ella los regidores, ministros y oficiales de la ciudad.

El escenario principal de las demostraciones festivas es la plaza, que una cuadrilla, contratada al efecto, limpia en profundidad y deja preparada, al igual que la fuente, que es adornada poniéndole un «aderezo de dos bolas", realizadas por el latonero Diego de Torres.

Veinte cargas de juncia servirán para alfombrar las calles por donde ha de pasar el cortejo con el que se han de clausurar los actos.

Como es habitual en estas ocasiones, las casas del cabildo lucen luminarias en la víspera. Lo mismo sucede en muchas casas particulares en las que se instalan a petición del concejo.

Del mismo modo, en la plaza tienen lugar demostraciones pirotécnicas, con fuegos, cohetes y ruedas, que en esta ocasión son realizadas por el platero Jorge Muñoz.

Dispuesto el escenario urbano y anunciada la fiesta por el desfile, las luminarias y los fuegos, el propio día de la festividad tiene lugar la solemne función religiosa en la catedral y la procesión con la imagen de la Virgen. Para estos actos, la ciudad reparte entre sus regidores, ministros y oficiales las velas de cera que han de llevar. Esto supone --al igual que siempre sucede en estos casos - la partida de gastos más crecida.

Al mismo tiempo que se desarrollan estos actos litúrgicos y oficiales, se celebran otros de carácter más popular y eminentemente lúdicos. Éstos son los elementos que integran de una manera más directa al pueblo en las celebraciones festivas. De todas formas, no perdamos de vista el hecho de que el pueblo vive con gran intensidad los actos de culto -función litúrgica y procesión-, de una manera especial cuando la situación de crisis que empieza a ser acuciante y especialmente dura para los grupos más débiles de la sociedad, es decir, cuando los miedos y la inseguridad colectiva se multiplican.

En esta ocasión, dichos elementos se concretan en dos danzas o grupos de bailarines, que participan en la procesión, y cuyas vistosas vestiduras son alquiladas en Granada por el responsable de la organización. Además, otros dos grupos de danzas se encargan de crear ambiente festivo: una danza de negros y gitanos, con música de tambor, de utamborilillo" y de "adufe" (pandero morisco que tocaban las gitanas), y el baile de los hombres y de "seis gitanillos", a todos los cuales se les 
compraron zapatos y adornos para la ocasión y cuyos vestidos fueron decorados con estrellas de papel plateado; la otra danza es de «sarao», que solía celebrarse por la noche. También se contrató a un gitano «bolteador» o saltimbanqui, que realizaba sus ejercicios con su mujer.

Por último, la gran figura cómica y grotesca, que aparecía siempre en las procesiones del Corpus y que también está presente en estas fiestas de la Inmaculada: la Tarasca, para la que se hacen «cabeza, pescuezo y saya de lienzo».

Como se puede comprobar, es difícil distinguir lo profano de lo religioso en esta celebración, lo que nos hace remitirnos a la misma idea de una unidad trascendental o esencial en la concepción del mundo a la que nos referíamos antes y que está asumida por todo el pueblo.

En cuanto al aspecto económico, la cantidad dedicada a estas fiestas está relativamente lejos de las que se destinan a las mayores, y más en concreto al Corpus y a los Mártires. Para estas últimas la ciudad tiene licencia concedida por la Corona para gastar 1.000 ducados de las rentas de propios, aunque al final el coste se elevaba a una cantidad bastante más crecida, que solía ser extraída de alguna renta o pagada a modo particular por los mismos regidores en aras de que no se escatimen gastos y no se desluzca la fiesta, así como en aumento del prestigio de los organizadores.

Para las fiestas de la Inmaculada se emplearon los 300 ducados que el concejo había concedido en principio. Tal cantidad, que equivale a 112.200 maravedíes, estaba lejos de los 625.600 maravedíes que fueron gastados el mismo año de 1640 en el Corpus ${ }^{25}$.

Por otra parte, esta celebración adquiere una importancia especial en relación con las otras festividades religiosas que se extienden a lo largo del año, ya que mientras el cabildo destina 300 ducados a su celebración, lo que equivaldría a 3.300 reales -112.200 maravedies-, para otras fiestas votivas y patronales sólo concede una subvención de 200 reales, 0 lo que es lo mismo, 6.800 maravedíes, para ayudar a los gastos de la cera.

Como datos ilustrativos señalaremos que las partidas más elevadas corresponden al alquiler en Granada de las vestiduras para dos danzas, cuyo importe se eleva a 28.900 maravedíes -que se abonan en dos pla-

25 Pérez del Campo, L. y Quintana Toret, F. J., op. cit., pág. 147. 


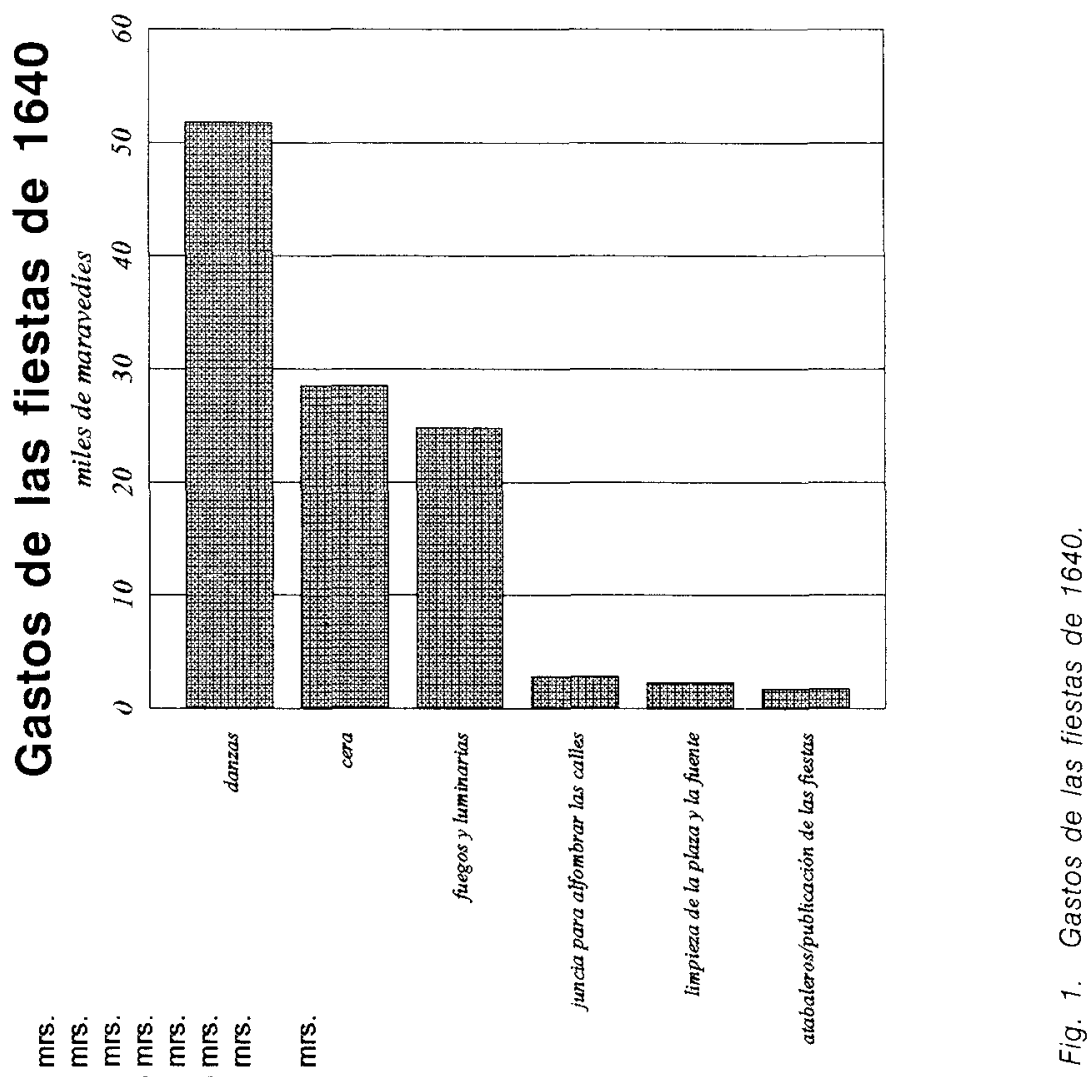



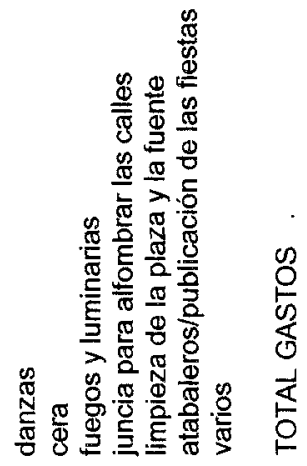




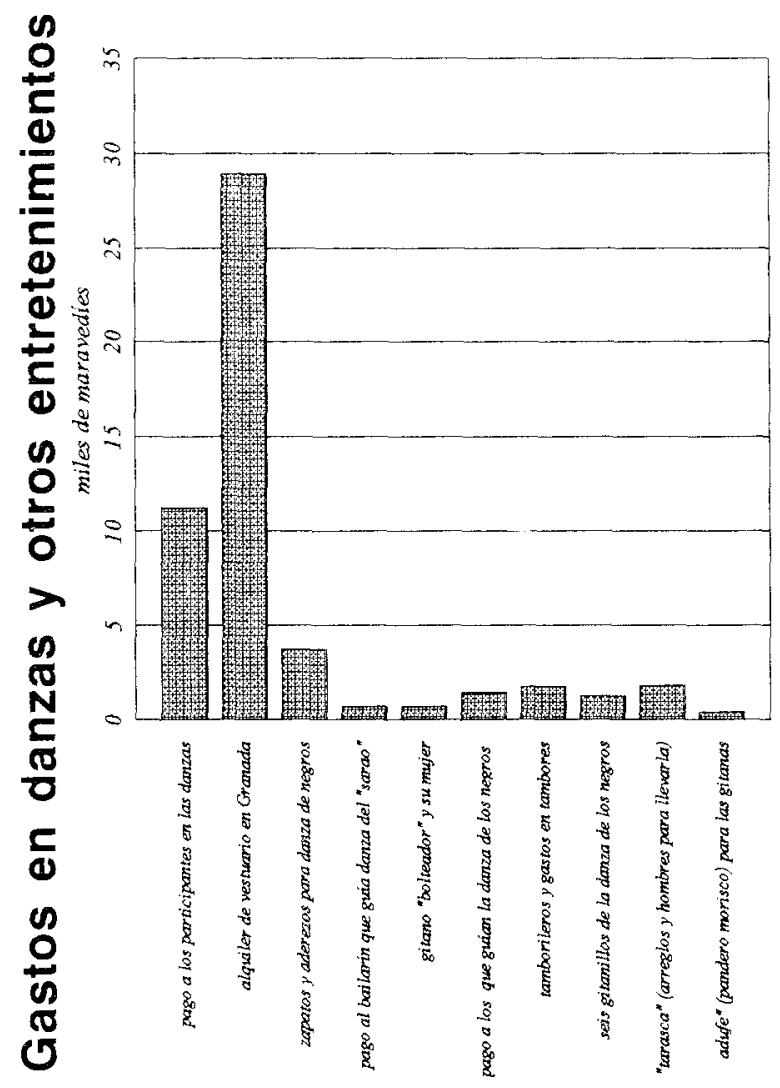


胥票

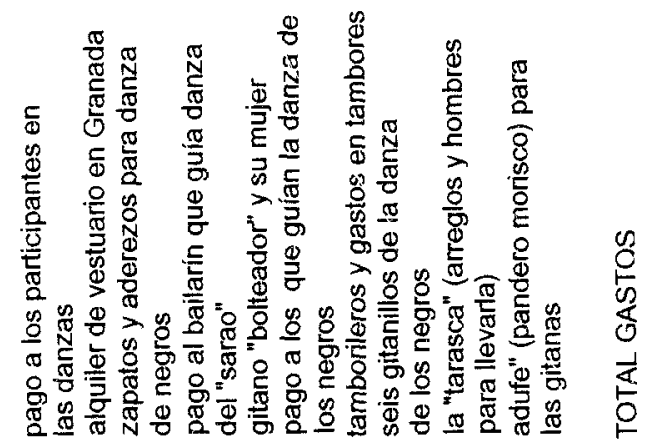


zos--, y a la cera que se ha de repartir, que cuesta 28.650 maravedíes. (fig. 1 y fig. 2).

En definitiva, las fiestas de la Inmaculada de 1640 reúnen todos los elementos prototípicos de la fiesta barroca de carácter religioso en cuanto a su organización, promoción, elementos integrantes e intencionalidad, hablándonos al mismo tiempo de la importancia de la devoción concepcionista en la Málaga del siglo XVII.

En el espacio urbano sacralizado por la presencia de templos parroquiales, conventos, ermitas, capillas y retablos callejeros, por la multiplicación de gestos de carácter religioso íntimamente relacionados con los actos vitales cotidianos, la celebración de estas fiestas de carácter sagrado vienen a reforzar las características de esa religiosidad, vivida y aparentada, promocionada desde los poderes civil y religioso que rigen en la ciudad, en el marco de la cultura del Barroco. 